\title{
An alternative treatment approach and follow-up of bone development ongoing young patient with extremely substance lost in anterior insicor teeth:
}

\section{case report}

\begin{abstract}
Objective: In this case report, endodontic and restorative treatment approaches have been reported in order to restore aesthetic and function in the lower and upper incisor teeth that have suffered from extreme material loss due to caries in a 14 year old patient.

Case: A 14-year-old woman who applied to our clinic for the restoration of the caries in the anterior teeth was diagnosed with clinic and radiographic examination and the patient was required to undergo endodontic treatment for the teeth numbered 11,12,31,32 and 41 . After the fiber post (TransLuma; BiscoInc.,Schaumburg, IL, ABD) treatment was applied to the teeth 11 and 12, direct restorations were made using self-etch adhesive (Clearfil SE Bond,Kuraray,Japonya) and composite material (Clearfil SE Bond, Kuraray, Japonya) since no prosthetic treatment was performed due to the age of the patient. The treatment of the caries in the other teeth of the patient was completed with the same composite material. Because of the necessity of follow-up of wide lesions on apicals of 31, 32, 41 which have no clinic crown, fiber-reinforced (Interlig; Angelus, Londrina, Brazilya) composite bridge performed as a long-term temporary restoration. The patient was given oral hygiene and was regularly checked every 6 months.
\end{abstract}

Conclusion: In this type of case, we believe that restorative treatment can be an effective treatment option for aesthetic and functioning as well as prosthetic treatment in patients with ongoing bone development.

Keywords: composite, fibre post, adhesive composite bridge

Volume 9 Issue 4 - 2018

Mediha Büyükgöze Dindar, Meltem Tekbaș
Atay
Department of Restorative Dentistry,Trakya University,Turkey

Correspondence: Mediha Büyükgöze Dindar, Research Assistant, Department of Restorative Dentistry, Faculty of Dentistry, Trakya University, Edirne, Turkey, Tel 05548229185, Email medihabuyukgoze@trakya.edu.tr

Received: August 06, 20I8 | Published: August 14, 2018

\section{Introduction}

The aesthetic and function of the oropharyngeal region are factors that affect quality of life regardless of personal factors such as age, gender and level of education. ${ }^{1}$ Anterior function and aesthetic deterioration due to tooth defect are frequently seen due to deep decay, trauma, periodontal disease, root resorption and failed endodontic treatments. The extraction of these teeth causes aesthetic, phonetic and functional difficulties, pathological migration in the teeth and psychological problems in patients. ${ }^{2}$ Urgent restoration of anterior aesthetic and functional requirements and treatment with minimal preparation that will cause minimal damage to the underlying dentition is important for patients. Current treatment options; removable temporary acrylic prostheses, dental prostheses used extracted tooth as abutment, fiber-reinforced adesive bridges, conventional metal and ceramic fixed partial prosthesis, and implant supported prostheses. When these treatment options are evaluated, the dentist must consider many factors, including the protection of natural teeth, minimal preparation, aesthetics and cost. ${ }^{3}$ Fiber-reinforced resin bridges are an alternative treatment for replacing missing teeth where minimal preparation is desired to preserve tooth structure.,

Adhesive bridges may be metal or fiber based. Adhesive bridges with metal structures have been used for many years. In a 13-year follow-up study of Zalkind et al. ${ }^{6}$ On metal-reinforced adhesive bridges, they reported that the mean retention times were 85 months $( \pm 13 \%$, 7 years). ${ }^{6}$ On the other hand, the reflection of the metal infrastructure in these bridge designs poses a problem in terms of aesthetics, and today the development of more aesthetic materials with high strengths limits their usage. ${ }^{7}$ For this reason, fiber-reinforced adesive bridges are more frequently preferred today. Another advantage of fiberreinforced adhesive bridges over metal-reinforced adhesive bridges is that the rigidity of the fiber infrastructure is less than the metal infrastructure and less stress is generated at the interfaces due to the low modulus of elasticity. ${ }^{8}$ Fiber reinforcement, on the other hand, is frequently used today because the composite alone has not succeeded in forming sufficient bonds to connect the pontic to the supporting tooth structure. ${ }^{9}$ Frese et al., ${ }^{10}$ reported $72.6 \%$ successful retention in 4.5 years of study on fibre-reinforced adhesive bridges. ${ }^{10}$ In systematic reviews of Van Heumen et al., ${ }^{11}$ for 4.5 years, this rate was reported as $73.4 \%{ }^{11}$ The most common failures of fiber-reinforced adhesive bridges are; failure of the bond with the composites due to cohesive strengths, ${ }^{12}$ debonding result from the dissolution of the adhesives ${ }^{13}$ and complete breakdown of the restoration. ${ }^{14} \mathrm{~A}$ complete breakdown of the fiber infrastructure is a rare complication. The incidence of fracture formation in fiber infrastructure can be reduced by increasing the type and amount of fibers used. ${ }^{15}$ Key factors which influences the physical properties of fibre-reinforced restorations are; quantity and degree of impregnation of fibers in polymer matrix, orientation of fibers, and adhesion of fibres to polymer matrix. ${ }^{16,17}$

In our study, it was aimed to restore aesthetic and function with fiber-reinforced adesive bridge until permanent prosthetic treatment of the lower incisor teeth, which had suffered extreme loss due to caries, is performed in the 14 years old patient during growth and development period. In this case report, the patient's treatment plan and 18 months follow-up results were reported. 


\section{Case presentation}

A 14-year-old woman who applied to our clinic for the restoration of the caries in the anterior teeth was diagnosed with clinic and radiographic examination and the patient was required to undergo endodontic treatment for the teeth numbered 11,12,31,32 and 41 (Figure 1) (Figure 2). In the patient who had no indications for permanent prosthetic treatment due to age, direct composite restoration was performed after the application of fiber post (TransLuma; BiscoInc., Schaumburg, IL, ABD) to the teeth 11 and 12. Restorations were completed by polymerizing (Valo, Ultradent Products, South Jordan, UT, USA) with self-etch adhesive (Clearfil SE Bond, Kuraray, Japan) and composite material (Beautifil B2, Shofu, Japan) (Figure 3) (Figure 4). The treatment of the caries in the other teeth of the patient was completed with the same composite material (Teeth 21, 22, 33 and 42). The tooth 42 , which is tilted to toothless area, is corrected during the filling process so that the two pontics can fit to the gap.

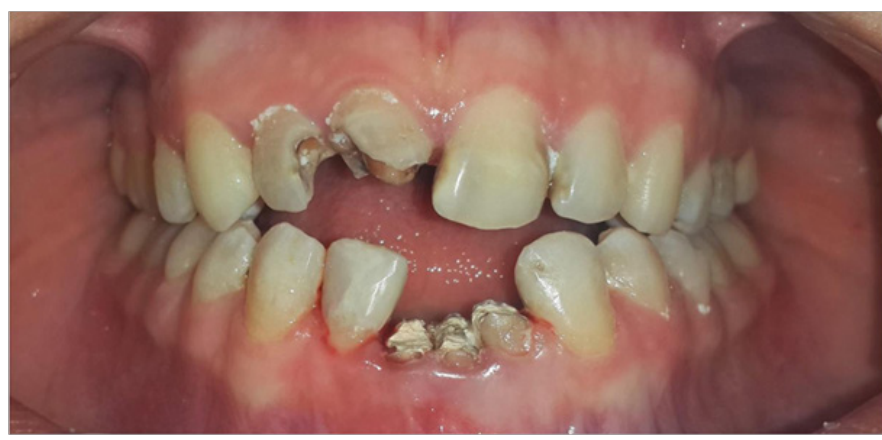

Figure I Facial view of initial situation.

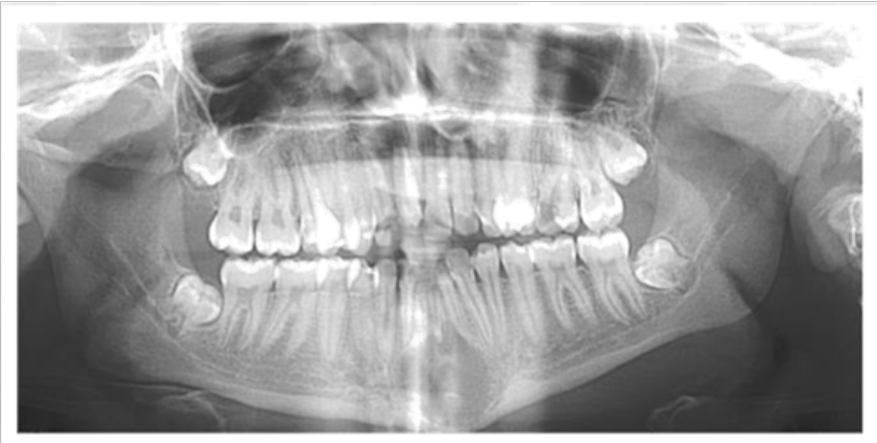

Figure 2 Radiography of the initial status.

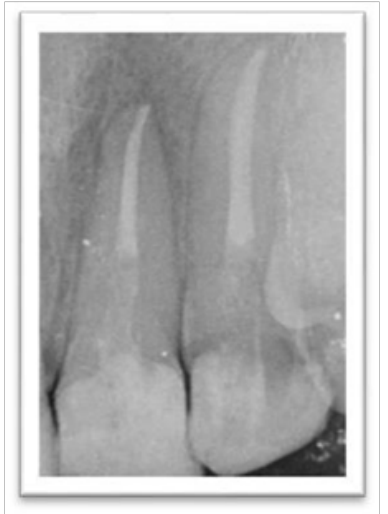

Figure 3 Radiograph of upper teeth.
Long-term follow-up of large lesions apical to teeth 31, 32, 41 without clinical crowns was necessary. During the follow-up period, fiber-reinforced composite bridge performed as a long-term temporary restoration. As teeth 33 and 42 moved toward the toothless area, it was determined that only 2 teeth could fit into the decreasing gap. Dental impression was taken with a hydrocolloid material (Kromopan, Lascod, Firenze, Italy) from the lower jaw of the patient and a stone cast was obtained using Type III dental stone (Fujirock, GC Company, Germany). The impregnated glass fiber was adjusted on the stone cast to measure the distance to include the neighboring teeth. The teeth to be used as pontics were formed by free modeling according to the manufacturer's instructions using the indirect composite resin (Gradia, Tokyo, Japan, DA2, E2) and the pontics prepared in the indirect composite oven (GC labolight duo, Japan) (Figures 5-9).

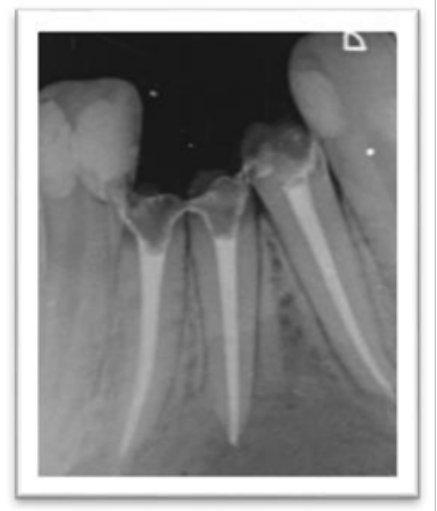

Figure 4 Radiograph of lower teeth.

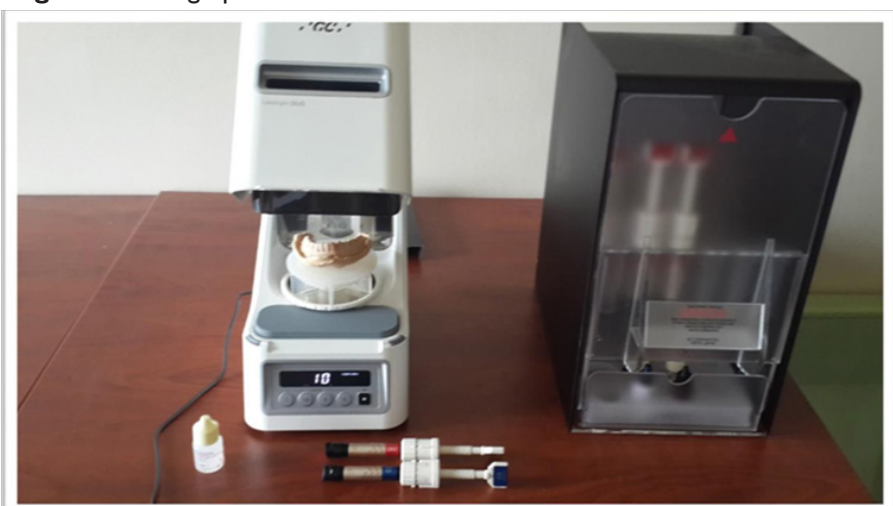

Figure $\mathbf{5}$ Indirect composite pontic preparation.

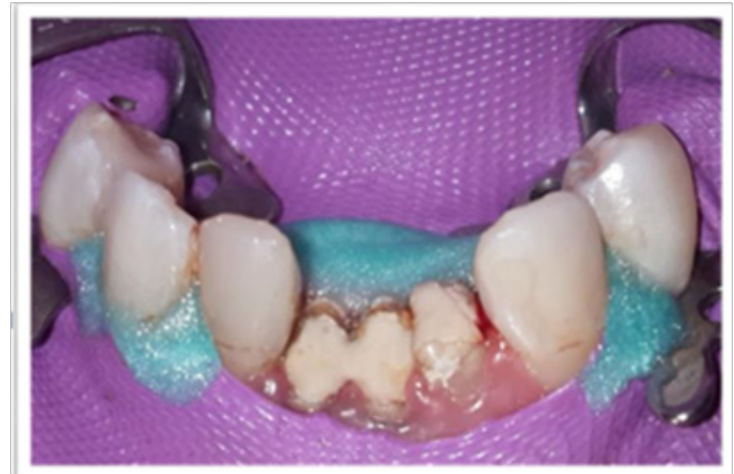

Figure 6 After rubber-dam applications. 


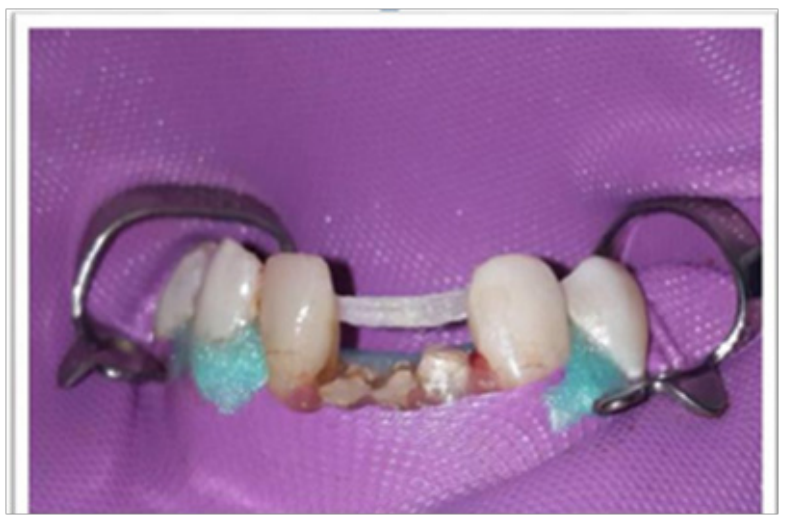

Figure 7 During fibre replacement.

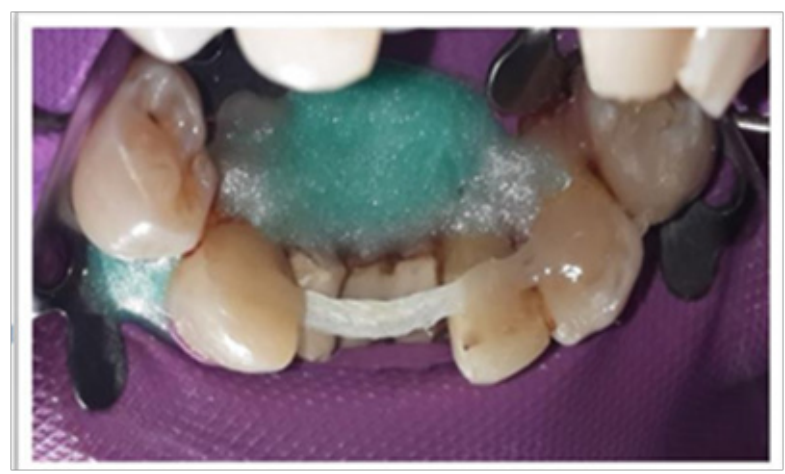

Figure 8 Lingual view of fibre.

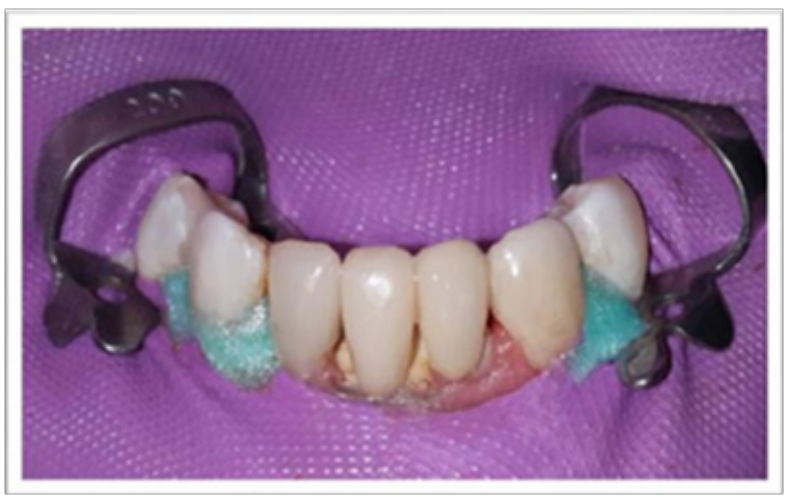

Figure 9 Final restoration.

The fibers were polymerized with light source (VALO, Ultradent Products, South Jordan, UT, USA) for $20 \mathrm{sec}$ by applying self-etch adhesive (Clearfil SE Bond, Kuraray, Japan) to adjacent teeth and pontics. All the surfaces to which the fiber was to be placed were coated with a thin layer of flowable composite (Beautifil Flow plus, Shofu, Japan) and glass fiber (Interlig, Angelus, Londrina, Brazil) was placed. The applied glass fiber was polymerized in every direction for 20 seconds. The prepared pontics were adjusted and polymerized using a flowable composite. Restoration was smoothed by finishing diamond burs and polishing disks. The patient was given oral hygiene training and regular 6-month controls were planned. There were no problems in the 6 and 12 month control of the patient. At 18 months of follow-up, mild edema in the gums of the patient and plaque accumulation in the cervical of the teeth were detected. The patient was given oral hygiene training and was called to regular check-ups (Figures 10-13).

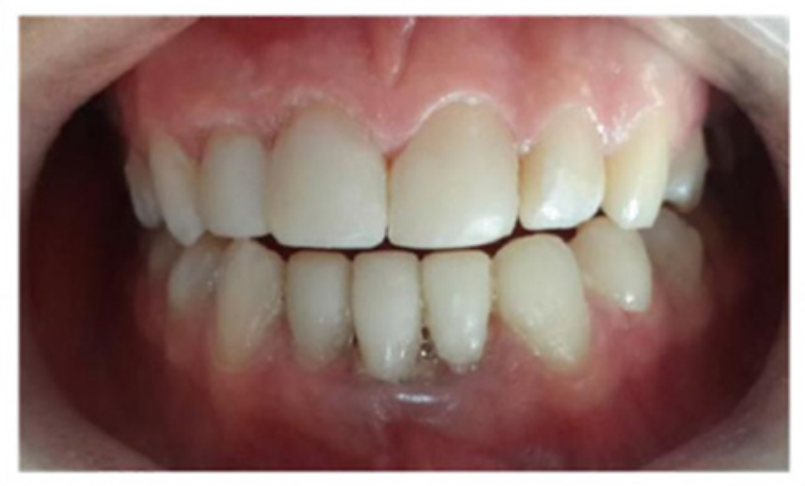

Figure 10 After treatment.

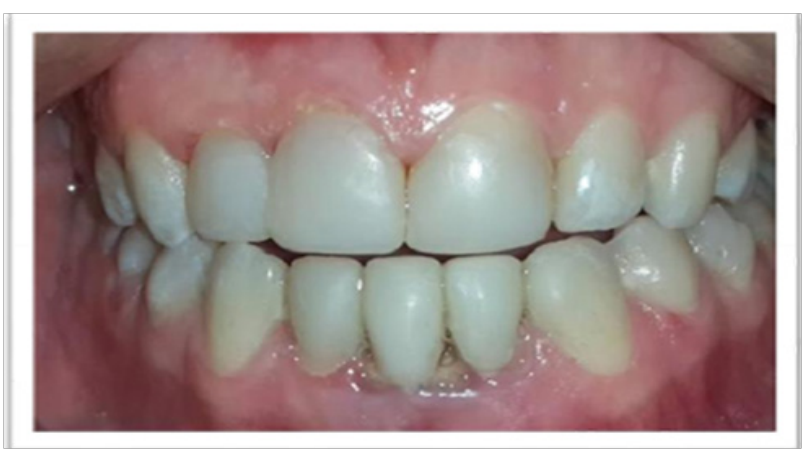

Figure II 6 months recall.

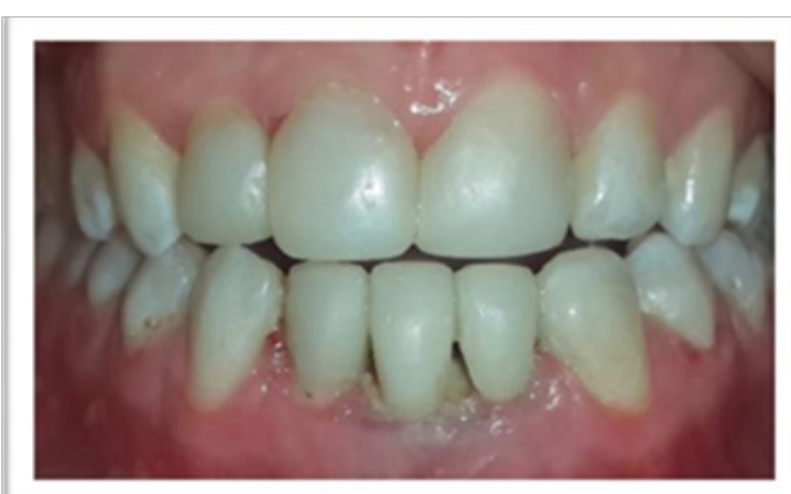

Figure I 2 I 2 months recall.

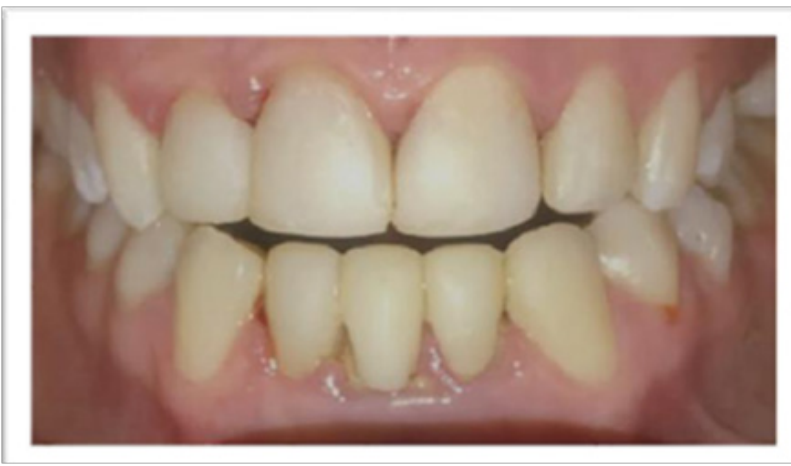

Figure 1318 months recall. 


\section{Discussion}

At an early age tooth extraction causes resorption of alveolar bone, shortening of the arch length, and has negative effects to the prosthetic treatment to be performed when the patient's jaw development ceases. It is important that the teeth that are planned to be extracted kept in the mouth with various treatments to save the arch from shortening. ${ }^{18}$ Extracted should be done just a short period of time before the prosthesis.

As a result of these reasons, after prosthetic, endodontic and orthodontic evaluations, treatment was planned. In this case, it was decided that all the roots should be kept in the mouth during the follow-up time for the lesion on the apical of $31,32,41$ so that the arch length would not be further shortened and the bone resorption was prevented. When the growth and development of the patient ceased, it was decided to extract one of the remaining roots cause the existing space is only enough for 2 teeth to fit, and that the remaining roots would be extrused and porcelain crowns will be performed after the fiber post application.

Another type of treatment that can be applied to the patient in this type of situation is to extract the teeth that are suffering from the loss of excessive material and to make a conventional metal ceramic partial prosthesis. Conventional metal ceramic prostheses exhibit maximum strength against incoming forces. On the other hand, they are not aesthetic, may cause allergies and necessity of preparing the abutment teeth ${ }^{19}$ are the issues that should be taken into consideration in planning the treatment in younger patients.

Another treatment option is tooth extraction and implant placement, but implants are not appropriate to perform before growth and development are completed, usually before the age of 18 years. The implants made before the completion of the growth and development period remain in the infra-arch and the high costs are the facts that implants are not preferred in these cases. ${ }^{20}$

It is necessary to wait a long time for permanent prosthetic restoration in young patients who are in the period of growth and development. Within this waiting period, protecting the aesthetics, function, and phonetics of the patient is important for patient's health and psychology. Partially removable prostheses can be made for young patients whose growth and development period has not been completed. Although these prostheses can be modified by the addition of acrylic resin when necessary, they have disadvantages such as not being comfortable to use, frequent breakage, causing the patient's oral hygiene to deteriorate and irritating the tissues. ${ }^{21}$ In patients whose growth and development period is not complete, the metal-reinforced adesive bridge elastic modulus is not preferred due to their low modulus. ${ }^{10}$ Considering all these disadvantages, removable temporary prosthesis is not preferred in order to traumatize the remaining tissues of the tooth roots. In this case report, providing aesthetic and function with adhesive composite bridge as a long-term temporary restoration is a non-invasive treatment option instead of all these treatment options and expected to result in positive physical and psychological consequences for young patients during the growth and development period.

Fiber-reinforced adhesive bridging may contain kevlar carbon, glass fibre, or pelletized fiber. ${ }^{22,23}$ Pre-impregnated glass fibres are prefered due to the advantages; their favorable optical properties, tensile stresses and crack propagation in the resin matrix compared to kevlar, polyethylene and carbon fibers. ${ }^{24}$ Interline-Angelus glass fibres used in this case are pre-impregnated, easily interceptable, and can be applied with lightly cured composite resin. ${ }^{25}$

In fiber-reinforced adhesive bridges, pontics can be made from acrylic, porcelain, composite materials or the extracted teeth of the patient. ${ }^{26}$ Due to the weak connection of the acrylic teeth to the fibre structure ${ }^{19}$ and high cost of the porcelain teeth, we preferred to use pontics made from composite. Composite pontics can be made directly or indirectly. Compared to the direct technique, the adaptation, surface smoothing and polymerization of the pontics made with indirect technique, is more successful. ${ }^{20}$ It requires more time to make pontic with direct technique while being made in the mouth and it is very difficult to remove the excess material, and it is also more easily colored. For these reasons, the pontics used in our study were made indirectly and the pontics were adjusted to the fiber structure within the mouth. Care was taken to leave a space between the pontics and the root of the tooth which the patient could comfortably provide oral hygiene. As a result, fibre-reinforced adhesive bridges are shortterm treatment alternatives where adequate aesthetics and function can be achieved as long as they are applied with the right indications.

\section{Conclusion}

Fiber-reinforced adhesive bridges are an affordable and aesthetic treatment option for younger patients. Regular and long-term followup studies are required for the fiber-reinfroced adhesive bridge application, which is a minimally invasive treatment approach for younger individuals during growth and development. In similar cases as we presented, it is possible to increase the usage of fiber-reinforced composite bridges for a temporary period with decreasing costs.

\section{Acknowledgements}

None.

\section{Conflict of interest}

The author declares that there is no conflict of interest.

\section{References}

1. AL-Omiri MK, Karasneh JA, Lynch E, et al. Impacts of missing upper anterior teeth on daily living. Int Dent J. 2009;59(3):127-132.

2. Raj R, Mehrotra K, Narayan I, et al. Natural Tooth Pontic: An Instant Esthetic Option for Periodontally Compromised Teeth-A Case Series. Case reports in dentistry. 2016;1-6.

3. Purra AR, Mushtaq M. Aesthetic replacement of an anterior tooth using the natural tooth as a pontic; an innovative technique. Saudi Dent J. 2013;25(3):125-128.

4. Vallittu PK, Sevelius C. Resin-bonded, glass fiber-reinforced composite fixed partial dentures: a clinical study. J Prosthet Dent. 2000;84(4):413-418.

5. Pjetursson BE, Thoma D, Jung R, et al. A systematic review of the survival and complication rates of implant-supported fixed dental prostheses (FDP s) after a mean observation period of at least 5 years. Clin Oral Implants Res. 2012;23 Suppl 6:22-38.

6. Zalkind M, Ever-Hadani P, Hochman N. Resin-bonded fixed partial denture retention: a retrospective 13-year follow-up. Journal of oral rehabilitation. 2003;30(10):971-977.

7. Goodacre CJ, Bernal G, Rungcharassaeng K, et al. Clinical complications in fixed prosthodontics. The Journal of prosthetic dentistry. 2003;90(1):31-41. 
8. Gül P, Akgül N. Fiber Reinforced Composite Bridge Applications in Anterior Tooth Deficiency: Two Case Reports. Turkiye Klinikleri Journal of Dental Sciences. 2015;21(2):173-178.

9. Junior G, de Aquino A, Lopes MWF, et al. Comparative study of flexura strength and elasticity modulus in two types of direct fiber-reinforced systems. Braz oral res. 2009;23(3):236-240.

10. Frese C, Schiller P, Staehle HJ, et al. Fiber-reinforced composite fixed dental prostheses in the anterior area: a 4.5-year follow-up. $J$ Prosthet Dent. 2014;112(2):143-149.

11. Van Heumen C, Kreulen CM, Creugers NH. Clinical studies of fiberreinforced resin-bonded fixed partial dentures: a systematic review. Eur J Oral Sci. 2009;117(1):1-6.

12. Culy G, Tyas MJ. Direct resin-bonded, fibre-reinforced anterior bridges: A clinical report. Australian Dental Journal. 1998;43(1):1-4.

13. Pjetursson BE, Tan WC, Tan K. A systematic review of the survival and complication rates of resin-bonded bridges after an observation period of at least 5 years. Clinical Oral Implants Res. 2008;19(2):131-41.

14. Wolff D, Wohlrab T, Saure D, et al. Fiber-reinforced composite fixed dental prostheses: A 4-year prospective clinical trial evaluating survival, quality, and effects on surrounding periodontal tissues. J Prosthet Dent. 2018;119(1):47-52.

15. Eminkahyagil N, Erkut S. An Innovative Approach to Chairside Provisional Replacement of an Extracted Anterior Tooth: Use of Fiber-Reinforced Ribbon-Composites and a Natural Tooth. Journal of Prosthodontics. 2006;15(5):316-320.

16. Ganesh M, Tandon S. Versatility of ribbond in contemporary denta practice. Trends Biomater Artif Organs. 2006;20(1):53-58.
17. Vallittu PK. Flexural properties of acrylic resin polymers reinforced with unidirectional and woven glass fibers. $J$ Prosthet Dent. 1999;81(3):318-326.

18. Terlaje RD, Donly KJ. Treatment planning for space maintenance in the primary and mixed dentition. ASDC J Dent Child. 2001;68(2):109-114.

19. Turker SB, Sener ID. Replacement of a maxillary central incisor using a polyethylene fiber-reinforced composite resin fixed partial denture: a clinical report. Journal of Prosthetic Dentistry. 2008;100(4):254-258.

20. Chafaie A, Portier R. Anterior fiber-reinforced composite resin bridge: a case report. Pediatr Dent. 2004;26(6):530-534.

21. Tüzüner T, Kuşgöz A, Nur BG. Temporary management of permanen central incisors loss caused by trauma in primary dentition with natural crowns: a case report. Dent Traumatol. 2009;25(5):522-526.

22. Butterworth C, Ellakwa AE, Shortall A. Fibre-reinforced composites in restorative dentistry. Dental update. 2003;30(6):300-306.

23. Ellakwa AE, Shortall AC, Marquis PM. Influence of fiber type and wetting agent on the flexural properties of an indirect fiber reinforced composite. $J$ Prosthet Dent. 2002;88(5):485-490.

24. Loose M, Rosentritt M, Leibrock A, et al. In vitro study of fracture strength and marginal adaptation of fibre-reinforced-composite versus all ceramic fixed partial dentures. Eur J Prosthodont Restor Dent. 1998;6(2):55-62.

25. Bechir ES, Pacurar M, Hantoiu TA. Aspects in effectiveness of glass and polyethylene fiber reinforced composite resin in periodontal splinting. Materiale plastice. 2016;53:104-109.

26. Van Heumen CC, van Dijken JW, Tanner J, et al. Five-year survival of 3-unit fiber-reinforced composite fixed partial dentures in the anterior area. Dent Mater. 2009;25(6):820-827. 